\title{
Article
}

\section{The Strength of Inconel 625, Manufactured by the Method of Direct Laser Deposition under Sub-Microsecond Load Duration}

\author{
Vladimir Promakhov ${ }^{1, *}$, Nikita Schulz ${ }^{1, *}$, Alexander Vorozhtsov ${ }^{1}$, Andrey Savinykh ${ }^{1,2}$, Gennady Garkushin ${ }^{2}{ }^{\mathbb{D}}$, \\ Sergey Razorenov ${ }^{2}$ and Olga Klimova-Korsmik ${ }^{1}$ \\ 1 Scientific and Educational Center "Additive Technologies", National Research Tomsk State University, \\ Lenin Avenue 36, 634050 Tomsk, Russia; abv@mail.tomsknet.ru (A.V.); savas@ficp.ac.ru (A.S.); \\ o.klimova@ltc.ru (O.K.-K.) \\ 2 Department of Extreme States of Matter, Institute of Problems of Chemical Physics of RAS, \\ 142432 Chernogolovka, Russia; garkushin@ficp.ac.ru (G.G.); razsv@ficp.ac.ru (S.R.) \\ * Correspondence: vvpromakhov@mail.ru (V.P.); schulznikita97@gmail.com (N.S.)
}

check for updates

Citation: Promakhov, V.; Schulz, N.; Vorozhtsov, A.; Savinykh, A.; Garkushin, G.; Razorenov, S.; Klimova-Korsmik, O. The Strength of Inconel 625, Manufactured by the Method of Direct Laser Deposition under Sub-Microsecond Load Duration. Metals 2021, 11, 1796. https://doi.org/10.3390/met11111796

Academic Editor: Aleksander Lisiecki

Received: 23 September 2021

Accepted: 4 November 2021

Published: 8 November 2021

Publisher's Note: MDPI stays neutral with regard to jurisdictional claims in published maps and institutional affiliations.

Copyright: (c) 2021 by the authors. Licensee MDPI, Basel, Switzerland. This article is an open access article distributed under the terms and conditions of the Creative Commons Attribution (CC BY) license (https:// creativecommons.org/licenses/by/ $4.0 /)$.

\begin{abstract}
This paper presents the results of measurements of the spall strength and elastic-plastic proper-ties, under dynamic and static loads, of the high-strength heat-resistant nickel-chromium alloy Inconel 625, obtained by the direct laser deposition method. The structural parameters of the obtained samples and the mechanical properties during static tests were studied. According to our information, anisotropy in the structural parameters operates primarily at the level of plastic deformation of alloys. Shock compression of the additive alloy Inconel 625 samples in the range of 6-18 GPa was carried out using a light-gas gun, both along and perpendicular to the direction of the deposition. The strength characteristics were determined from the analysis of the shock wave profiles, which were recorded using the VISAR laser velocimeter during the loading of samples. It was found that the value of the spall strength of additive samples does not depend on the direction of deposition, and the Hugoniot elastic limit of samples loaded perpendicular to the deposition direction is about $\sim 10 \%$ higher. With an increase in the maximum compression stress, the material's spall strength increases slightly, but for both types of samples, a slight decrease in the Hugoniot elastic limit was observed as the compression stresses increase. On the basis of the measured wave profiles, shock Hugoniots of the samples of the alloy Inconel 625, loaded both along and perpendicular to the direction of deposition, are constructed in this pressure range.
\end{abstract}

Keywords: alloy Inconel 625; direct laser deposition; shock wave; spall fracture; Hugoniot elastic limit

\section{Introduction}

Active research on the capabilities of additive manufacturing of metallic materials is currently underway [1-5]. The subjects of the research are mechanical, tribological, and corrosion related properties, as well as structural and phase-shift analysis of the fabricat-ed metallic items. The approaches of additive manufacturing methods differ in the type of material fed into the system (powder, wire), heat source (laser, electron beam, or electric arc), and the medium where item fabrication is taking place (vacuum or atmosphere with shielding gas). The powder approach, in turn, can be implemented either by selective fusion of the material in a local bath of the melt (PBF, powder bed fusion), or by direct feeding of the powder to the focus of the heat source (DED, direct energy deposition). The most common materials that are used for studying the patterns of structure formation in additive manufacturing are austenitic steels and alloys based on nickel, titanium, aluminium, and copper. For these types of materials, technologies for obtaining high-quality structures with high properties have already been well developed [3-5].

Nevertheless, there is little literature presenting systematic research results of the mechanical properties of materials obtained using additive manufacturing technologies under conditions of dynamic loading [6-12]. It is evident that there is a need for using parts 
and constructions fabricated by additive manufacturing in extreme operating conditions, such as very high or low temperatures and pulse and impact loading; hence, a need has emerged for obtaining information on the dynamic strength of such materials. With the development of methods for fabricating materials using additive manufacturing technologies, reports, with the measurements of their elastoplastic and strength properties under shock-wave loading, started to occasionally appear, as well as their comparisons with the properties of materials obtained by traditional metallurgical methods. Comparative shock wave loading experiments in the pressure range of 0.2-7.0 GPa with the 304L steel [6] have shown that additively manufactured samples have significantly higher tear strength and Hugoniot elastic limit (HEL) compared to the original steel samples. The research work of Brown et al. [7] compared the elastic-plastic and strength properties under shock-wave loading of the titanium alloy Ti-6Al-4V obtained by electron beam melting (EBM) and laser metal deposition (LMD) in both horizontal and vertical deposition directions. An insignificant difference was revealed in both the measured spall strength and the Hugoniot elastic limit in 4 sample types. The research work of Jones et al. [8], involving a similar titanium alloy Ti-6Al-4V obtained using selective laser sintering (SLM), has revealed a decrease in spall strength by $40 \%$, compared to the forged item. In the research work of Razorenov et al. [9], no anisotropy of the strength properties of Ti-6Al-4V titanium samples obtained by direct laser deposition was revealed. A slight increase in the spall strength and Hugoniot elastic limit in these samples was found, in comparison with the heat-treated rolled titanium alloy VT6. The research work of Zaretsky et al. [10] did not reveal a dependency between the dynamic characteristics and the orientation of shockwave loading of AlSi10Mg alloy samples that were produced by selective laser melting (SLM). The dynamic yield stress of the AISi10Mg alloy obtained by SLM is almost twice that of its cast counterpart, and the spall strength is four times higher than that of the cast alloy. The research work of Gray et al. [11] revealed a strong dependency between the orientation of the Hugoniot elastic limit and the spall strength of tantalum samples that were fabricated using additive manufacturing. The value of the Hugoniot elastic limit of the material that was fabricated by additive manufacturing is two times higher than that of the annealed forged material, while the spall strength is lower by $20-30 \%$. The samples of $09 \mathrm{CrNi} 2 \mathrm{MoCu}$ steel obtained by the DLD method demonstrate a strong dependence of the strength properties under shock-wave loading on subsequent heat treatment, and the value of their spall strength is slightly lower than that of hot-rolled samples [12]. Thus, the aim of this work is to study the structural parameters and mechanical characteristics during dynamic fracture of the Inconel 625 alloy in order to reveal the possible parameters of the anisotropy of the properties of materials obtained using additive technologies. The data obtained are novel for understanding the mechanisms of destruction of materials obtained using additive technologies.

\section{Materials and Methods}

Samples of Inconel 625 that were obtained using direct laser deposition were used as a material for investigation. The samples were obtained from powders produced by Höganäs AB, Höganäs, Sweden. The chemical composition of the powders is provided in Table 1.

Table 1. Chemical composition of Inconel 625 powder.

\begin{tabular}{cccccccccc}
\hline \multirow{2}{*}{ Manufacturer } & \multicolumn{10}{c}{ Chemical Composition of Powders, wt.\% } \\
\cline { 2 - 10 } & $\mathbf{N i}$ & $\mathbf{C r}$ & $\mathbf{F e}$ & $\mathbf{M o}$ & $\mathbf{S i}$ & $\mathbf{N b}$ & $\mathbf{M n}$ & $\mathbf{O}_{2}$ & Other \\
\hline $\begin{array}{c}\text { Inconel 625 } \\
\text { Höganäs AB }\end{array}$ & Main & 20.8 & 0.51 & 8.9 & 0.43 & 3.51 & 0.37 & 0.07 & 0.08 \\
\hline
\end{tabular}

Direct laser deposition was carried out in a laser facility that comprised of the LRM-200iD_7L industrial robot (Fanuc, Oshino, Yamanashi, Japan), the LK-700 laser irradiation source (IPG 
Photonics, Oxford, MA, USA), the FLW D30 laser head (IPG Photonics) with a COAX-40-S coaxial nozzle (Fraunhofer ILT, Aachen, Germany), the Powder Feeder Twin 150 (Oerlikon Metco, Pfeffikon, Switzerland), and a process cabin. The samples were obtained with the following parameters of laser deposition: radiation power- $-1300 \mathrm{~W}$, productivity $-20 \mathrm{~mm} / \mathrm{s}$, layer step $-0.4 \mathrm{~mm}$, beam diameter $-1 \mathrm{~mm}$, powder consumption $-5.3 \mathrm{~g} / \mathrm{min}$. The diameter of the gas-powder mixture at the focal point of the laser is about $1 \mathrm{~mm}$.

For shock wave experiments, special samples were prepared from Inconel 625 that was obtained by direct laser deposition, and the nominal thickness of the samples was $2 \mathrm{~mm}$. The samples under study were cut from a workpiece in two directions: perpendicular to the deposition axis and along it. Figure 1 shows the scheme of the direction of loading of the samples, which was carried out along the deposition direction and perpendicular to it. The density of the samples, measured by hydrostatic weighing, was $\rho_{0}=8.422 \mathrm{~g} / \mathrm{cm}^{3}$. The measured longitudinal speed of the sound was $C_{1}=5.607 \mathrm{~km} / \mathrm{s}$, along the deposition direction, and $5.751 \mathrm{~km} / \mathrm{s}$, perpendicular to the deposition direction.

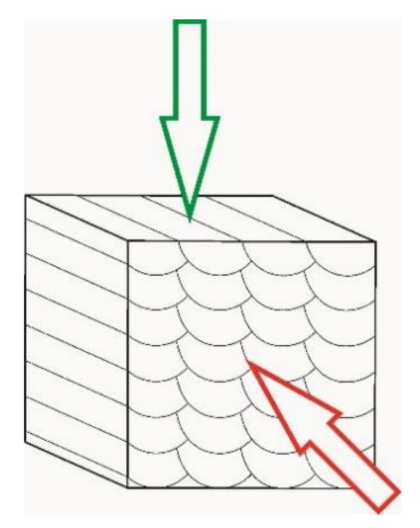

Figure 1. Schematic representation of shock wave loading of the samples relative to the deposition direction (green arrow-perpendicular to the deposition axis, red arrow-along the deposition axis).

Shock wave experiments were carried out using a gas barrel unit, wherein the impactor was accelerated (air or helium was used as an accelerating gas) in the velocity range of $230 \pm 10 \mathrm{~m} / \mathrm{s}$ to $670 \pm 10 \mathrm{~m} / \mathrm{s}$, which corresponds to the maximum compressive stress in the test material between 6 and $18 \mathrm{GPa}$. The compressed gas accelerated a hollow cylinder made of aluminium or magnesium, to which a $5 \mathrm{~mm}$ thick polymethyl methacrylate disk was glued on the side of the sample, and to which, in turn, the impactor was glued. The ratio between the impactor thickness and the sample thickness was $\sim 1 / 4$, with the exception of experiments with the lowest impactor velocity where the impactor/sample thickness ratio was $\sim 1 / 2$.

Copper or tungsten was used as the material for the impactors, and experimental samples thicknesses $h_{s}$, impactor thicknesses $h_{\text {imp }}$, and impactor velocities $V_{\text {imp }}$ are presented in Table 2 A polymethylmethacrylate substrate was used to prevent impactor flexing during acceleration, and the entire unit was vacuumed before each experiment. In the experiments, impactor velocity and tilt were monitored by electric contact sensors, and a VISAR (Velocity Interferometer System for Any Reflection) [13] was used to monitor the velocity profile $\mathrm{u}_{\mathrm{fs}}(\mathrm{t})$ of the free rear surface of the sample, with a temporal resolution of $\sim 1 \mathrm{~ns}$. The experimental scheme used for the determination of high strain rate properties is shown in Figure 2. 
Table 2. Loading conditions and the results of calculations of the shock adiabatic coefficients for the additively manufactured alloy Inconel 625 (i.e., In625), along the deposition direction and perpendicular to it.

\begin{tabular}{cccccc}
\hline Sample & $\mathbf{h}_{\mathbf{s}}, \mathbf{m m}$ & $\begin{array}{c}\mathbf{h}_{\mathbf{i m p}}, \mathbf{m m} / \\
\text { Material }\end{array}$ & $\mathbf{V}_{\mathbf{i m p}}, \mathbf{m} / \mathbf{s}$ & $\boldsymbol{U}_{\boldsymbol{S}}, \mathbf{k m} / \mathbf{s}$ & $\boldsymbol{u}_{\boldsymbol{p}}, \mathbf{k m} / \mathbf{s}$ \\
\hline \multicolumn{5}{c}{ Along the Deposition Direction } \\
\hline In625_2 & 1.944 & $0.465 / \mathrm{Cu}$ & $675 \pm 10$ & 4.972 & 0.2978 \\
In625_3 & 1.957 & $0.395 / \mathrm{W}$ & $638 \pm 10$ & 5.124 & 0.4055 \\
In625_4 & 1.952 & $0.786 / \mathrm{Cu}$ & $234 \pm 10$ & 4.646 & 0.106 \\
In625_51 & 1.940 & $0.463 / \mathrm{Cu}$ & $350 \pm 10$ & 4.763 & 0.1538 \\
\hline \multicolumn{7}{c}{ Perpendicular to the Deposition Direction } \\
\hline pIn625_6 & 2.067 & $0.480 / \mathrm{Cu}$ & $350 \pm 10$ & 4.741 & 0.1452 \\
pIn625_7 & 2.007 & $0.802 / \mathrm{Cu}$ & $234 \pm 10$ & 4.682 & 0.1105 \\
pIn625_8 & 1.964 & $0.480 / \mathrm{Cu}$ & $675 \pm 10$ & 4.935 & 0.298 \\
pIn625_9 & 1.995 & $0.396 / \mathrm{W}$ & $638 \pm 10$ & 5.178 & 0.407 \\
\hline
\end{tabular}

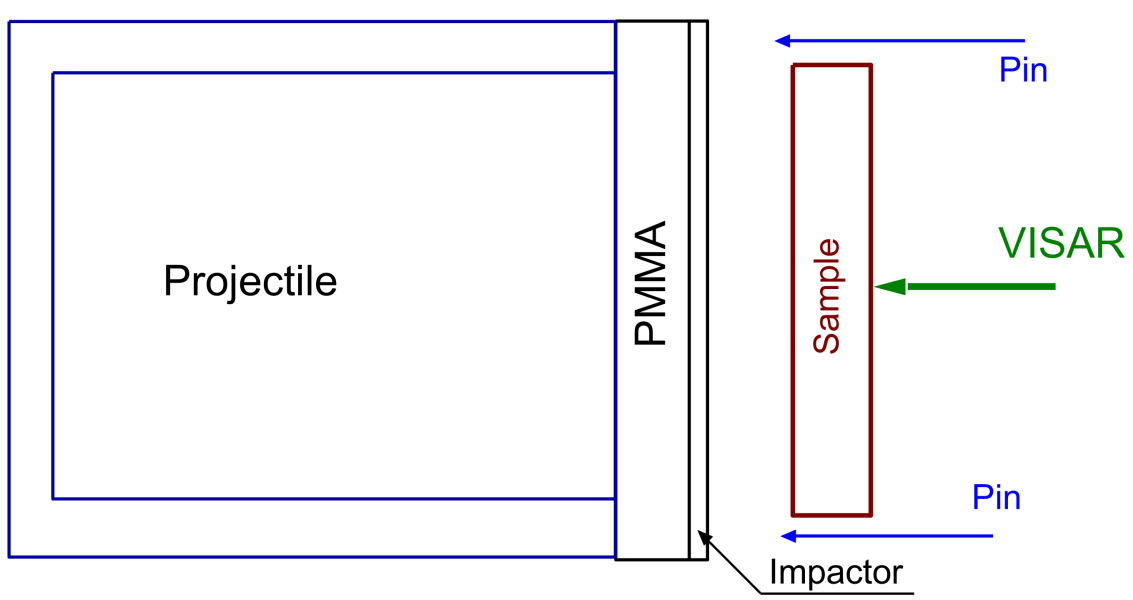

Figure 2. Schematic of experiments on recording the velocity profiles of the free surface of the samples of the additively manufactured Inconel 625 alloy.

\section{Results and Discussion}

To identify the features of the structural parameters of materials, studies were carried out using optical and scanning electron microscopy. The studies of the microstructure of alloy Inconel 625 samples that were obtained by direct laser deposition show significant differences between samples with longitudinal (Figure 3a) and perpendicular (Figure 3b) direction of deposition. During laser exposure on the powder material, it melts and subsequently crystallises [14]. The temperature gradient that is formed during solidification is directed perpendicular to the boundaries of the melt bath [15]. These crystallisation conditions cause the directed deposition of crystallites from the periphery of the melt zone to its centre. The presence of pores with a size of 10-200 microns, inside which there are unalloyed powder particles, is established (see Figure 3b). Such defects have a significant impact on the mechanical properties [16].

In both cases, ductile fracture is characteristic; however, in the samples that were cut perpendicular to the growth direction, more unfused powder particles are present at the fractures, thus, in this direction during fracture, the presence of unfused particles plays an important role, compared with the samples that were cut along the growth direction. A more detailed study (Figure 4) shows that the entire surface of the alloy consists of pits, similar in size and morphology to the cellular-dendritic structure of the alloy microstructure. It is shown that in a plane parallel to the growth direction, pores are observed that are located along the boundaries of the visible melt baths, and they have a flat shape. Such pores occur due to the lack of fusion of the molten metal powder with the substrate on 
which it is applied [16]. Such a phenomenon can occur due to various reasons, particularly due to the uneven thickness of the applied layer, the ingress of non-metallic inclusions into the melt region, etc.

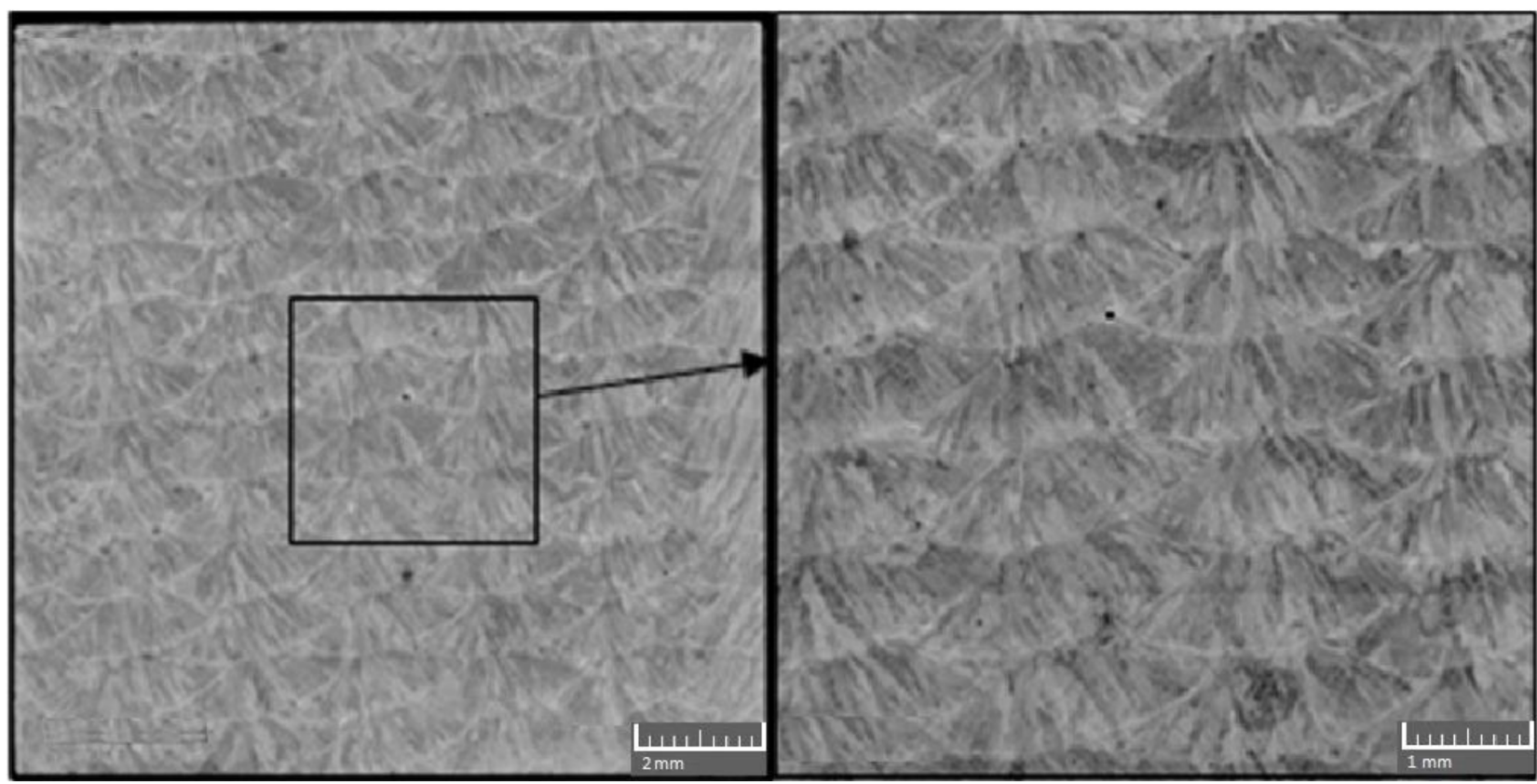

(a)

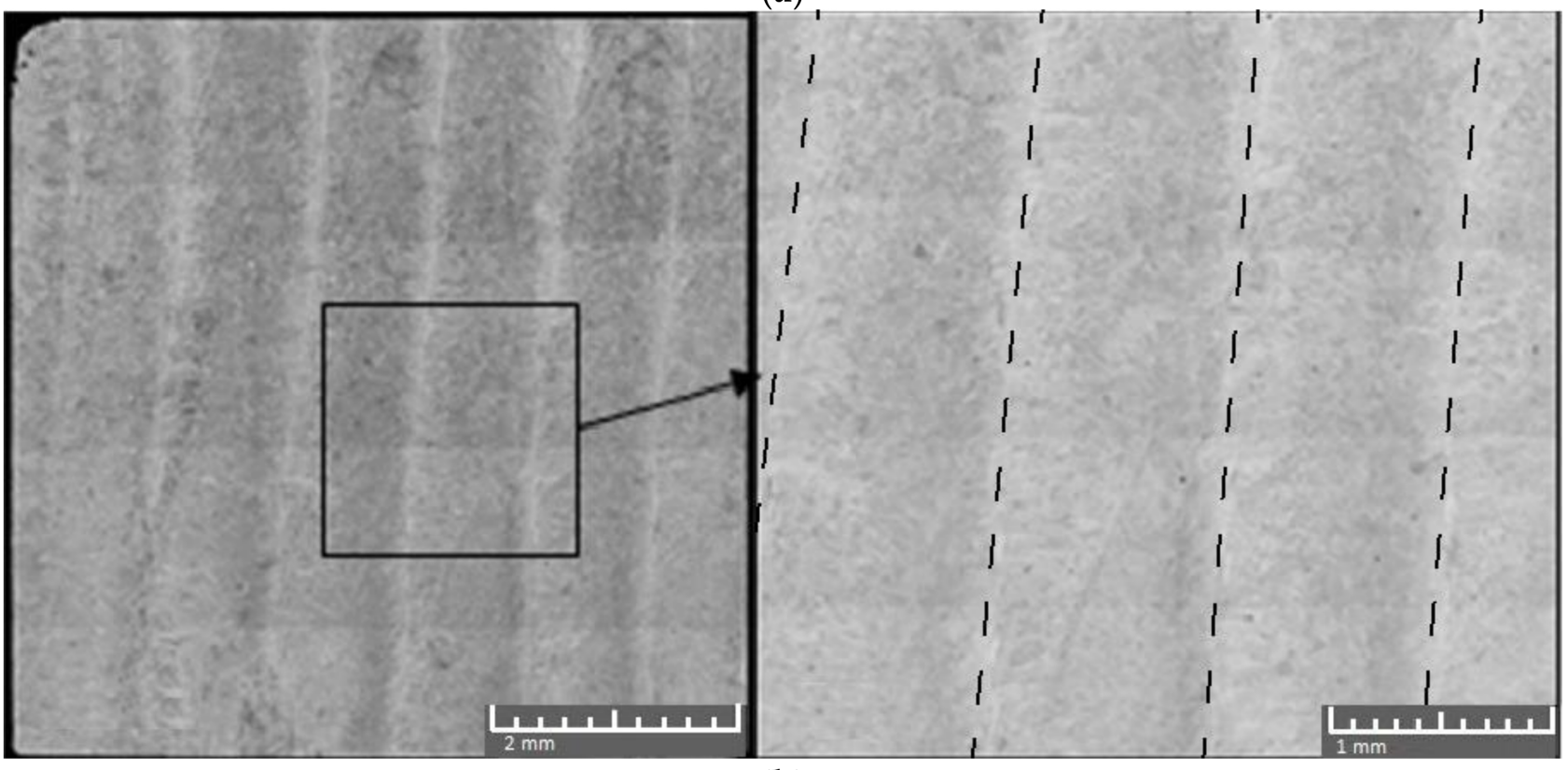

(b)

Figure 3. Microstructure of samples of the additively manufactured alloy Inconel 625 along (a) and perpendicular (b) to the growth direction. 


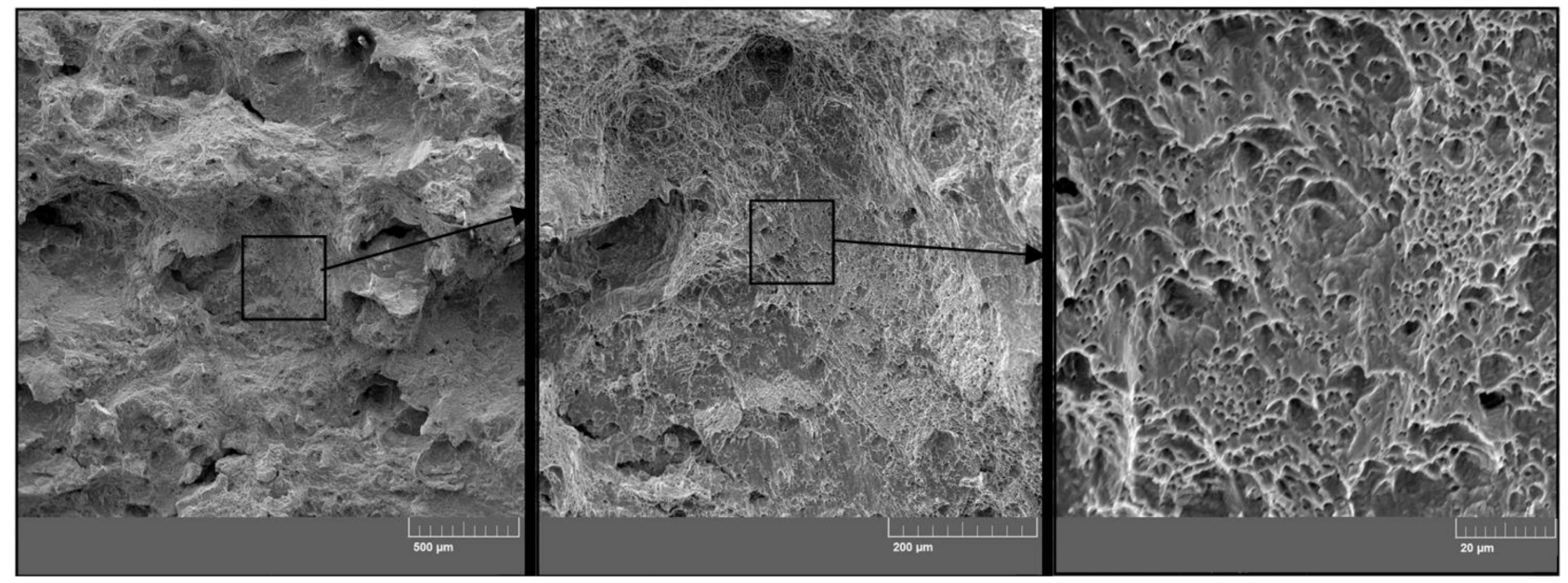

(a)

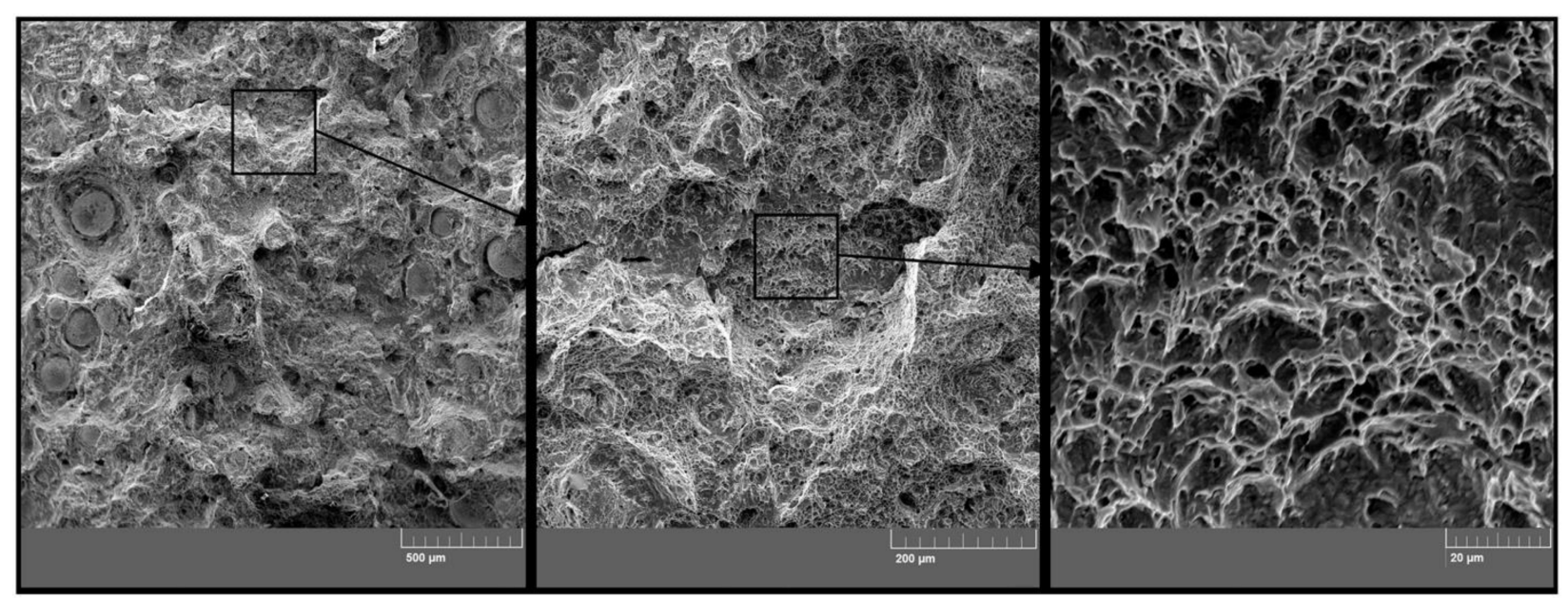

(b)

Figure 4. Structure of the fracture surface of the samples of additively manufactured alloy Inconel 625 along (a) and perpendicular (b) to the growth direction.

The factors affecting the present anisotropy of the mechanical properties of alloys made by direct laser deposition are [16]:

- residual tension, which is eliminated by thermal treatment;

- pores located perpendicular to the direction of deposition;

- features of the grain microstructure that are formed, depending on the parameters of direct laser deposition.

The layered structure of the grown samples is traced; this structure directly affects their mechanical properties, leading to the existence of a certain difference in the strength and plastic characteristics of the grown products. Figure 5 shows the tension-strain dependencies for the materials under study. It is shown that relatively insignificant differences are observed in the deformation behaviour. The elastic modulus along the deformation axis is $542 \mathrm{MPa}$, and in the perpendicular direction of the deformation axis it is $526 \mathrm{MPa}$. There are differences in the relative elongation. Anisotropy in the structural parameters operates primarily at the level of plastic deformation of alloys. 


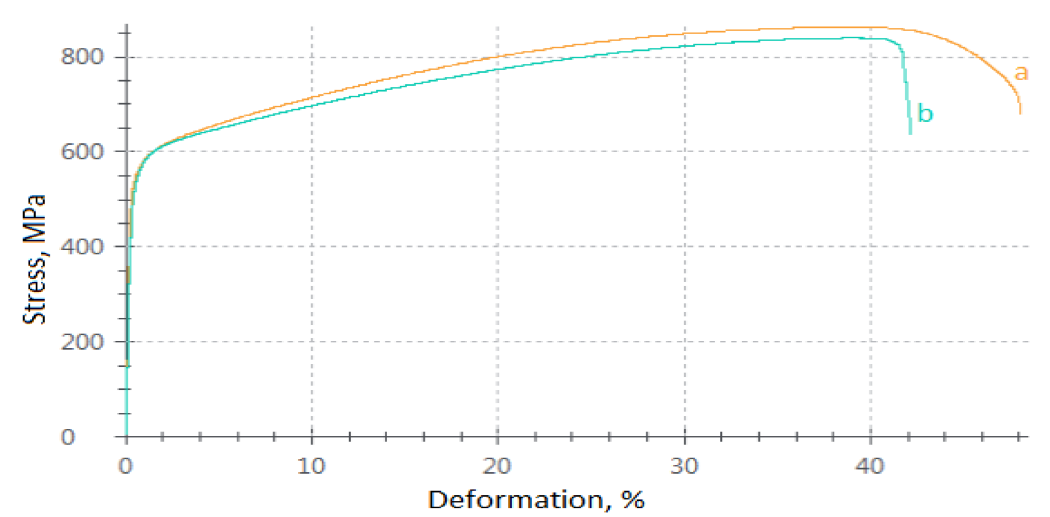

Figure 5. Stress-strain curves of additively manufactured alloy Inconel 625 along (a) and perpendicular (b) to the growth direction.

Figures 6 and 7 show the velocity histories of the free surface of alloy Inconel 625 samples along the deposition directions and perpendicular to them. On the free surface velocity profiles, the emergence of an elastic compression wave propagating with the longitudinal speed of the sound $C_{1}$ is recorded, then a plastic shock wave followed by a region of constant parameters is recorded, and finally, a part of the rarefaction wave is recorded. The amplitude of the elastic precursor is determined by the Hugoniot elastic limit (HEL) of the material, and this is calculated as follows:

$$
\sigma_{\mathrm{HEL}}=0.5 \rho_{0} \times u_{\mathrm{HEL}} \times C_{1}
$$

where $u_{\mathrm{HEL}}$ is the free surface velocity of the elastic wave in the precursor (see Figure 6).

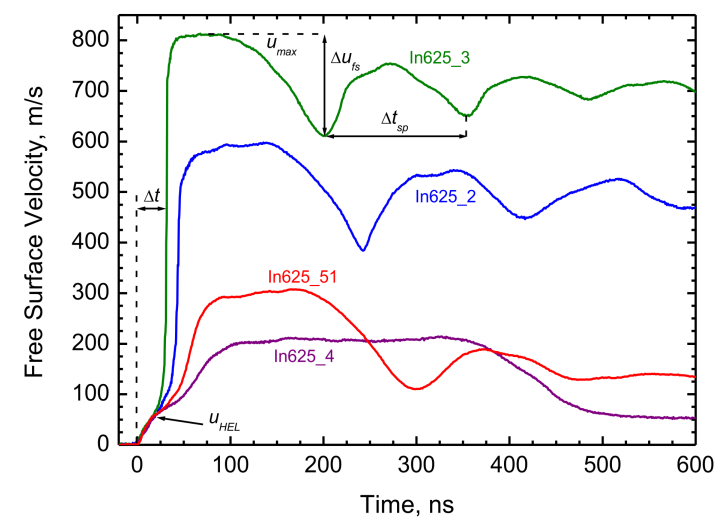

Figure 6. The velocity histories of the alloy Inconel 625 samples along deposition directions.

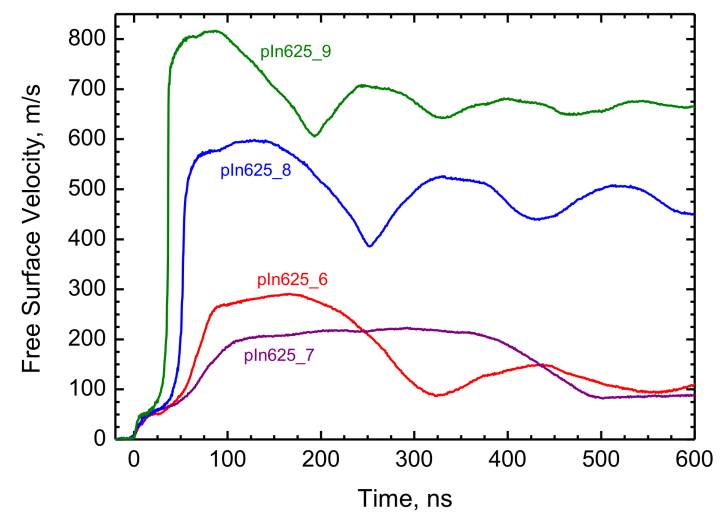

Figure 7. The velocity histories of the alloy Inconel 625 samples perpendicular to the deposition direction. 
After the reflection of the compression pulse from the free surface, tensile stresses are generated inside the sample, which result in the sample's fracture, i.e., spalling. The decrement of the surface velocity $\Delta u_{\mathrm{fs}}$ (Figure 6), as it decreases from the maximum to the value ahead of the front of the spall pulse, is proportional to the value of the fracturing stress, i.e., the spall strength of the material. In the linear (acoustic) approximation, the spall strength of the material is calculated as follows:

$$
\sigma_{\mathrm{sp}}=\frac{1}{2} \rho_{0} \times C_{\mathrm{b}} \times\left(\Delta u_{\mathrm{fs}}+\delta\right)
$$

where $\delta$ is the correction for the distortion of the velocity profile, due to the difference in the velocities of the elastic front of the spall pulse and the velocity of the plastic part of the incident unloading wave in front of it [17]. The spall thickness $h_{\mathrm{sp}}=C_{1} \Delta \mathrm{t}_{\mathrm{sp}} / 2$ was estimated from the oscillation period after spalling on the free surface velocity profile [18]. In the experiments under the lowest compression stress (Figures 6 and 7), spall fracture did not occur due to the low velocity of the impactor and the PMMA substrate located on the backside of the impactor, which prevented the impactor from unloading completely.

To calculate the spall strength according to Equation (2), it is necessary to know the bulk sound speed $C_{\mathrm{b}}$. It is known that the longitudinal speed of sound $C_{1}$ is related to the bulk sound speed via the relation $\frac{c_{l}^{2}}{c_{b}^{2}}=3 \frac{1-v}{1+v}$ where $v$ is the Poisson's ratio. The longitudinal speed of sound $C_{l}$ is related to the Young's modulus $E$, the Poisson's ratio and the initial density via the relation $c_{l}=\sqrt{\frac{E}{\rho} \frac{1-v}{(1+v)(1-2 v)}}$. From the reference data for the alloy Inconel 625, obtained in the solid solution state by casting, $E=204.8 \mathrm{GPa}, v=0.312$, and $\rho_{0}=8.440 \mathrm{~g} / \mathrm{cm}^{3}$. Calculations based on the above ratios and the available data for the alloy Inconel 625 obtained by casting yielded the following values: $C_{1}=5.815 \mathrm{~km} / \mathrm{s}$ and $C_{b}=4.636 \mathrm{~km} / \mathrm{s}$. The measured longitudinal sound speed for the additively obtained material demonstrates its dependency on the deposition direction and thus has lower values. Anisotropy will also manifest itself in the values of the Poisson's ratio that are not known for the additively manufactured alloy.

It is necessary to determine the bulk sound speed $c_{b}$ of an additively manufactured material under study in order to calculate the spall strength. It is necessary to determine the bulk sound speed from the linear dependency of the shock wave velocity on the particle velocity in the form $U_{S}=c_{0}+b u_{p}$, where $c_{0}$ takes the value of the bulk sound speed $c_{b}$ at zero particle velocity, and $\mathrm{b}$ is the inclination of the Hugoniot. To calculate the shock wave velocity, we use the relation presented by Kanel et al. [18]:

$$
U_{S}=c_{l} \frac{h_{s} / c_{l}-\Delta t / 2}{h_{s} / c_{l}+\Delta t / 2}
$$

Here $\Delta t$ is the difference in time between the emergence of the middle of the plastic part of the compression wave and the elastic part of the compression wave on the free surface (see Figure 8). Relation (3) takes into account the interactions between the incident wave and the reflected wave near the sample's surface. Particle velocity is defined as $u_{p}=u_{\max } / 2$, where $u_{\max }$ is the maximum value of the free surface velocity (see Figure 8). The obtained values of the shock wave velocity and particle velocity for the additively manufactured alloy Inconel 625, along the deposition direction and perpendicular to it, are presented in Table 3 and in Figure 8. The points obtained for both deposition directions for the alloy Inconel 625 can be described by the linear relationships $U_{S}=4.497+1.61 u_{p}$ when loaded perpendicular to the deposition direction, and by $U_{S}=4.502+1.55 \mathrm{u}_{\mathrm{p}}$ when loaded along the deposition direction. Figure 8 also shows the $U_{S}-u_{p}$ dependency for the alloy Inconel 738 [19]. The value of the bulk sound speed $C_{b}=4.636 \mathrm{~km} / \mathrm{s}$ for the cast alloy Inconel 625 lies practically on the linear dependency $U_{S}-u_{p}$ for the alloy Inconel 738. It can be seen from the figure that the Hugoniot elastic limits for the additively manufactured samples of the alloy Inconel 625 are situated somewhat lower, which may be associated with the existing insignificant porosity of the samples under study. 


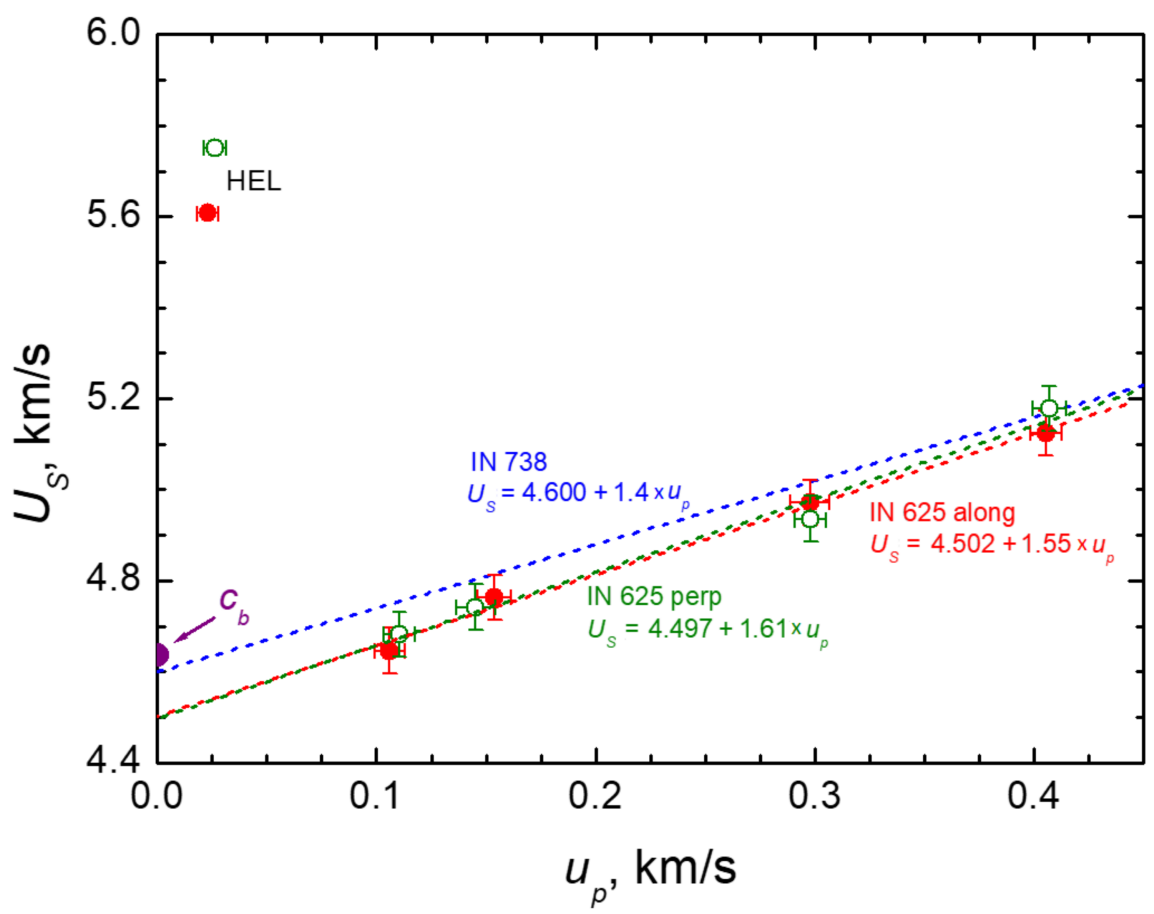

Figure 8. Dependence of the shock wave velocity on the particle velocity of the alloy Inconel 625 (i.e., IN 625), obtained by additive manufacturing under loading along the deposition direction and perpendicular to it. The value of bulk sound speed of Inconel 625, obtained by casting, is shown at $u_{p}=0$. Data for the alloy Inconel 738 (i.e., IN 738), have been presented [19].

Table 3. Results of measuring the elastic-plastic and strength properties under shock wave loading of an additively manufactured alloy Inconel 625 (i.e., In625) along the deposition direction and perpendicular to it.

\begin{tabular}{|c|c|c|c|c|c|c|c|c|}
\hline Sample & $u_{\mathrm{HEL}}, \mathrm{m} / \mathrm{s}$ & $\sigma_{\mathrm{HEL}}, \mathrm{GPa}$ & $\Delta \mathbf{u}_{\mathrm{fs}}, \mathrm{m} / \mathrm{s}$ & $\sigma_{\mathrm{sp}}, \mathrm{GPa}$ & $\dot{\mathbf{V}} / \mathbf{V}_{0}, \mathbf{s}^{-1}$ & $\mathrm{~h}_{\mathrm{sp}}, \mathrm{mm}$ & $\dot{\varepsilon}_{x}, \mathrm{~s}^{-1}$ & $\sigma_{x}, \mathrm{GPa}$ \\
\hline \multicolumn{9}{|c|}{ Along the Deposition Direction } \\
\hline In625_2 & 45.6 & 1.08 & 213.3 & 4.80 & $3.20 \times 10^{5}$ & 0.47 & $8.68 \times 10^{6}$ & 12.60 \\
\hline In625_3 & 43.5 & 1.03 & 204.6 & 4.58 & $3.07 \times 10^{5}$ & 0.41 & $34.13 \times 10^{6}$ & 17.59 \\
\hline In625_4 & 49.3 & 1.16 & - & - & - & - & $0.29 \times 10^{6}$ & 4.35 \\
\hline In625_51 & 49.3 & 1.16 & 197.5 & 4.35 & $2.52 \times 10^{5}$ & 0.60 & $0.82 \times 10^{6}$ & 6.34 \\
\hline \multicolumn{9}{|c|}{ Perpendicular to the Deposition Direction } \\
\hline pIn625_6 & 54.1 & 1.31 & 202.6 & 4.40 & $2.23 \times 10^{5}$ & 0.64 & $0.60 \times 10^{6}$ & 6.03 \\
\hline pIn625_7 & 55.5 & 1.34 & - & - & - & - & $0.30 \times 10^{6}$ & 4.61 \\
\hline pIn625_8 & 50.3 & 1.22 & 209.6 & 4.70 & $2.92 \times 10^{5}$ & 0.49 & $7.27 \times 10^{6}$ & 12.56 \\
\hline pIn625_9 & 51.2 & 1.24 & 207.6 & 4.47 & $2.49 \times 10^{5}$ & 0.38 & $31.37 \times 10^{6}$ & 17.87 \\
\hline
\end{tabular}

Figure 9 shows the $\sigma_{\text {HEL }}$ values obtained as a function of the maximum compressive stress $\sigma_{x}$ and which were calculated using relation (1) for the additive alloy Inconel 625 when loaded along the deposition direction and perpendicular to it. The maximum compressive stress in each experiment was calculated as $\sigma_{x}=\sigma_{H E L}+\rho_{0} U_{S}\left(u_{\max }-\right.$ $\left.u_{H E L}\right) / 2$ [20]. It can be seen that when the samples are loaded perpendicular to the deposition direction, they demonstrate higher values of the Hugoniot elastic limit in the investigated range of compressive stresses between 4 and $18 \mathrm{GPa}$, compared to the samples loaded along the deposition direction. In both cases, a slight decrease in $\sigma_{\mathrm{HEL}}$ is recorded as the compression stress is increased. Table 3 summarises the values of $u_{\mathrm{HEL}}, \sigma_{\mathrm{HEL}}$ and $\sigma_{x}$. A slight decrease in $\sigma_{\text {HEL }}$ with increasing pressure is due to the fact that, with increasing pressure, the deformation rate in the shock wave increases, which leads to an increase in the concentration of twins and a slight drop in the Hugoniot elastic limit, as was observed, for example, on titanium alloys [21]. 


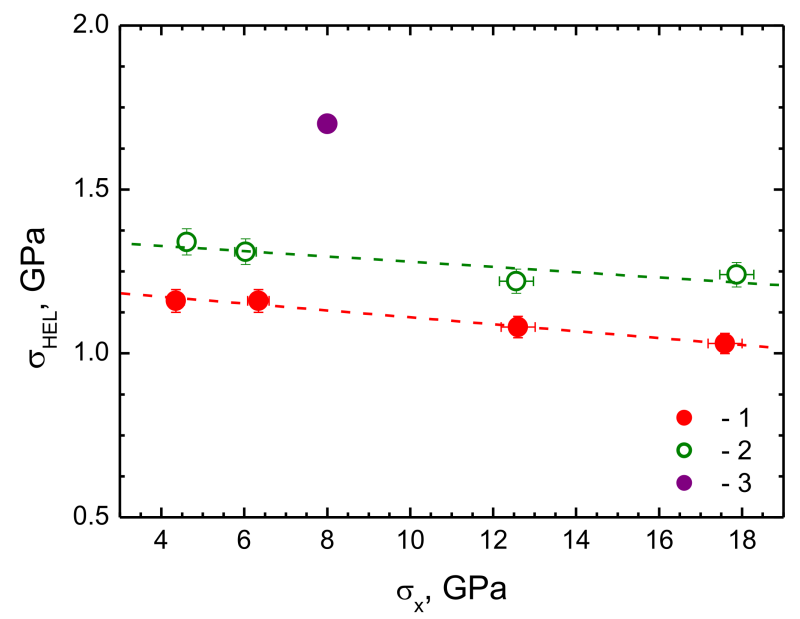

Figure 9. Dependency of the Hugoniot elastic limit on the maximum compressive stress of the alloy Inconel 625, obtained by additive manufacturing: 1-loading along the deposition direction; 2-loading perpendicular to the deposition direction; 3-Inconel 738 [19].

Spall strength values of the alloy Inconel 625, obtained by additive manufacturing, calculated using relation (2) under loading along the deposition direction and perpendicular to it are presented in Figure 10 and in Table 2. Table 3 also presents the calculated strain rates in the rarefaction wave using the ratio $\frac{\dot{V}}{V_{0}}=-\frac{\dot{u}_{f s r}}{2 C_{b}}$ [22] where $\dot{u}_{f s r}$ is the measured rate of velocity drop of the test sample's free surface in the unloading part of the shock compression pulse. Figure 10 shows that with an increase in the maximum compressive stress, the ability of the material to resist the maximum tensile stresses increases slightly. It should be noted that an increase in the spall strength is not related to an increase in the rate of deformation in the rarefaction wave (see Table 3). As a rule, the spall strength increases with an increase in the strain rate in the rarefaction wave but, such dependences are typically obtained at approximately one maximum compression stress $[23,24]$. In the research works [25-27], an insignificant increase in the spall strength of metals was noted, depending on the maximum compressive stress, the nature of which is similar to that obtained in the research work described in the present paper. The obtained spall strength values for the additively manufactured alloy Inconel 625 significantly exceed the spall strength values for the alloy Inconel 738 [19] obtained using conventional technology. However, the values of the Hugoniot elastic limit obtained in this work for the additively deposited alloy Inconel 625 are $~ 30 \%$ lower than those for the alloy Inconel 738 .

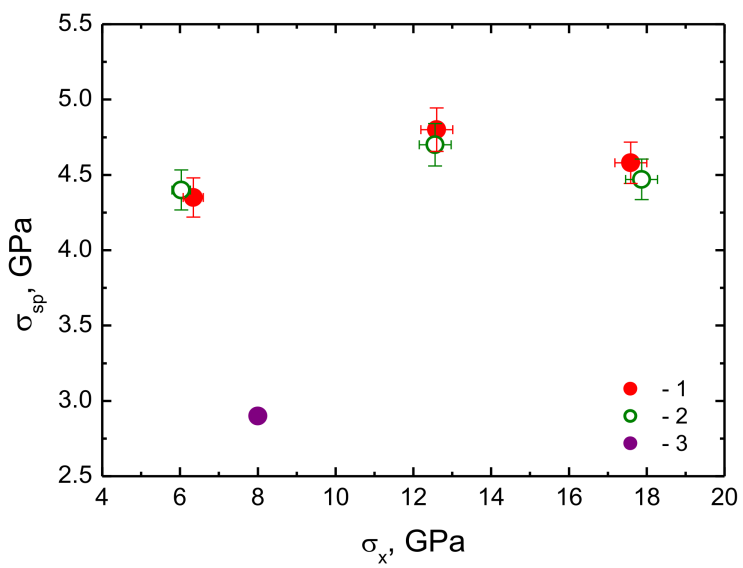

Figure 10. Dependency of the spall strength on the maximum compressive stress of the alloy Inconel 625 obtained by additive manufacturing: 1-loading along the deposition direction; 2-loading perpendicular to the deposition direction; 3-Inconel 738 [19]. 
The measured profiles of the free surface velocity at different maximum compressive stresses were used to determine the maximum compression rates in plastic shock waves. The compression rate was defined as $\dot{\varepsilon}_{x}=\dot{u}_{f s} / 2 U_{S}$, where $\dot{u}_{f_{S}}$ is the maximum surface acceleration in a plastic shock wave [28]. The calculation was performed assuming that the plastic shock wave is stationary or close to stationary. The results of evaluating the compression rate, depending on the maximum compressive stress behind the first plastic shock wave, are presented in Figure 11 and in Table 2. As can be seen in Figure 11, with an increase in the shock compression pressure, the compression rate in a plastic wave (both under loading along the deposition direction and perpendicular to it) changes in a similar way. The compression rate can be described by power-law dependencies on the maximum compression stress, $\dot{\varepsilon}_{x}=A\left(\sigma_{x} / \sigma_{0}\right)^{\beta}\left(\sigma_{0}=1 \mathrm{GPa}\right)$ [28], with indicator $\beta=3.4$ and coefficient $A$. Deposition directions affect coefficient $\mathrm{A}$ insignificantly, and the latter takes on the following values: $A=1800 \mathrm{~s}^{-1}$ along the deposition direction and $A=1500 \mathrm{~s}^{-1}$ perpendicular to it.

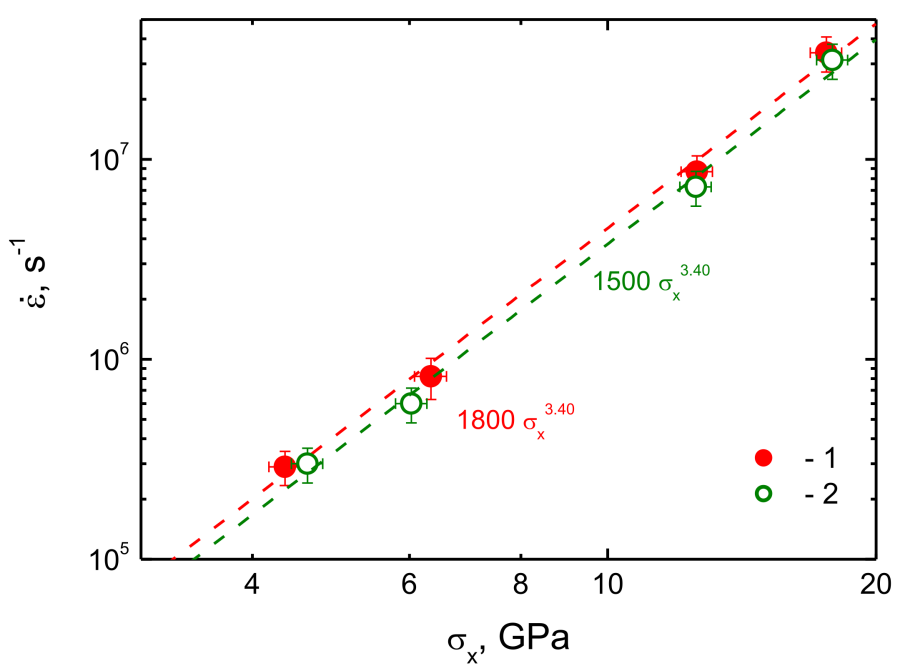

Figure 11. Dependency of the compression rate in a plastic shock wave on the final compression stress behind the wave of the alloy Inconel 625 obtained by additive manufacturing: 1-loading along the deposition direction; 2 -loading perpendicular to the deposition direction.

\section{Conclusions}

It is shown that the anisotropy of the structure of materials affects the mechanical properties during static tests. It is shown that relatively insignificant differences are observed in the deformation behaviour. The elastic modulus along the deformation axis is $542 \mathrm{MPa}$, and, in the perpendicular direction of the deformation axis, it is $526 \mathrm{MPa}$. There are differences in the relative elongation. As aforementioned, anisotropy in the structural parameters operates primarily at the level of plastic deformation of alloys. The factors affecting the present anisotropy of the mechanical properties of alloys made by direct laser deposition are: residual tension that is eliminated by thermal treatment; pores located perpendicular to the direction of deposition; features of the grain microstructure that are formed, depending on the parameters of direct laser deposition. The spall strength and the Hugoniot elastic limit were measured, shock Hugoniots were constructed, and the compression rate in the plastic shock wave of alloy Inconel 625 samples, obtained by the direct laser deposition method, was determined in the compression stress range of 6-18 GPa. The measurements were carried out along and perpendicular to the direction of deposition of the samples. The measurements showed that there is a negligible (i.e., practically absent) influence of the deposition direction relative to the impact direction on the dependence of the shock wave velocity vs. the particle velocity and the value of the spall strength. There is also no anisotropy of the power-law indicator of the dependence of the compression rate on the compression stress. The value of the Hugoniot elastic limit of samples, when loaded 
perpendicular to the deposition direction, is higher by $\sim 10 \%$ of its values for samples loaded along the deposition direction. At the same time, in both cases, a slight decrease in this value is observed with an increase in the pressure of shock compression, while the resistance of samples of both types increases slightly.

Author Contributions: Conceptualisation, V.P., A.S. and S.R.; methodology, A.S., O.K.-K. and S.R.; investigation, A.S., V.P., N.S., O.K.-K. and G.G.; writing—original draft preparation, A.S., V.P., N.S., O.K.-K., G.G. and A.V.; writing—review and editing, S.R., A.S., G.G. and V.P. All authors have read and agreed to the published version of the manuscript.

Funding: The work was supported by the Ministry of Science and Higher Education of the Russian Federation (agreement No. 075-15-2020-785 (Agreement with Joint Institute for High Temperatures RAS)).

Institutional Review Board Statement: Not applicable.

Informed Consent Statement: Not applicable.

Data Availability Statement: Not applicable.

Conflicts of Interest: The authors declare no conflict of interest. The funders had no role in the design of the study; in the collection, analyses, or interpretation of data; in the writing of the manuscript; or in the decision to publish the results.

\section{References}

1. Debroy, T.; Wei, H.L.; Zuback, L.S.; Mukherjee, T.; Elmer, J.W.; Milewski, J.O.; Beese, A.M.; Wilson-Heid, A.; De, A.; Zhang, W. Additive manufacturing of metallic components-Process, structure and properties. Prog. Mater. Sci. 2018, 92, 112-224. [CrossRef]

2. Promakhov, V.V.; Savinykh, A.S.; Dubkova, Y.A.; Grunt, N.V.; Razorenov, S.V. Strength Properties of Aluminum-Oxide Ceramics Prepared by the Additive Manufacturing Method under Shock-Wave Loading. Tech. Phys. Lett. 2018, 44, 898-901. [CrossRef]

3. Gorsse, S.; Hutchinson, C.; Goune, M.; Banerjee, R. Additive manufacturing of metals: A brief review of the characteristic microstructures and properties of steels, Ti-6Al-4V and high-entropy alloys. Sci. Technol. Adv. Mater. 2017, 18, 584-610. [CrossRef]

4. Promakhov, V.; Zhukov, A.; Ziatdinov, M.; Turichin, G.; Perminov, A. Inconel 625/TiB 2 metal matrix composites by direct laser deposition. Metals 2019, 9, 141. [CrossRef]

5. Basak, A.; Das, S. Epitaxy and Microstructure Evolution in Metal Additive Manufacturing. Annu. Rev. Mater. Res. 2016, 46, 125-149. [CrossRef]

6. Wise, J.L.; Adams, D.P.; Nishida, E.E.; Song, B.; Maguire, M.C.; Carroll, J.; Reedlunn, B.; Bishop, J.E.; Palmer, T.A. Comparative shock response of additively manufactured versus conventionally wrought 304L stainless steel. AIP Conf. Proc. 2017, 1793, 100015.

7. Brown, A.D.; Ameri, A.H.; Gregg, A.; Austin, D.C.; Escobedo, J.P.; Hazell, P.J.; East, D.; Quadir, M.Z. Dynamic mechanical response of additive manufactured Ti-6Al-4V. AIP Conf. Proc. 2018, 1979, 070008.

8. Jones, D.R.; Fensin, S.J.; Dippo, O.; Beal, R.A.; Livescu, V.; Martinez, D.T.; Trujillo, C.P.; Florando, J.N.; Kumar, M.; Gray, G.T. Spall fracture in additive manufactured Ti-6Al-4V. J. Appl. Phys. 2016, 120, 135902. [CrossRef]

9. Razorenov, S.V.; Garkushin, G.V.; Savinykh, A.S.; Klimova-Korsmik, O.G.; Shalova, S.A.; Gushchina, M.O. Dynamic strength of the VT6 titanium alloy obtained by direct laser growth. Phys. Mesomech. 2021, 24, 17-25.

10. Zaretsky, E.; Stern, A.; Frage, N. Dynamic response of AlSi10Mg alloy fabricated by selective laser melting. Mater. Sci. Eng. A 2017, 688, 364-370. [CrossRef]

11. Gray, G.T.; Knapp, C.M.; Jones, D.R.; Livescu, V.; Fenshin, S.; Morrow, B.M.; Trujillo, C.P.; Martinez, D.T.; Valdez, J.A. Structure/property characterization of spallation in wrought and additively manufactured tantalum. AIP Conf. Proc. 2018, 1979, 060002.

12. Klimova-Korsmik, O.; Turichin, G.; Mendagaliev, R.; Razorenov, S.; Garkushin, G.; Savinykh, A.; Korsmik, R. High-Strain Deformation and Spallation Strength of 09CrNi2MoCu Steel Obtained by Direct Laser Deposition. Metals 2021, 11, 1305. [CrossRef]

13. Barker, L.M.; Hollenbach, R.E. Laser interferometer for measuring high velocities of any reflecting surface. J. Appl. Phys. 1972, 43, 4669. [CrossRef]

14. Wong, H.; Dawson, K.; Ravi, G.A.; Howlett, L.; Jones, R.O.; Sutcliffe, C.J. Multi-Laser Powder Bed Fusion Benchmarking-Initial Trials with Inconel 625. Int. J. Adv. Manuf. Technol. 2019, 105, 2891-2906. [CrossRef]

15. Verdi, D.; Garrido, M.A.; Munez, C.J.; Poza, P. Mechanical properties of Inconel 625 laser cladded coatings: Depth sensing indentation analysis. Mater. Sci. Eng. A 2014, 598, 15-21. [CrossRef]

16. Mazur, M.; Benoit, M.; Easton, M.; Brandt, M. Selective laser melting of Inconel 625 alloy with reduced defect formation. J. Laser Appl. 2020, 32, 022058. [CrossRef] 
17. Kanel, G.I. Distortion of the Wave Profiles in an Elastoplastic Body upon Spalling. J. Appl. Mech. Tech. Phys. 2001, 42, 358-362. [CrossRef]

18. Kanel, G.I.; Razorenov, S.V.; Fortov, V.E. Shock-Wave Phenomena and the Properties of Condensed Matter, 1st ed.; Springer: New York, NY, USA, 2004.

19. Zaretsky, E.B.; Kanel, G.I.; Razorenov, S.V.; Baumung, K. Impact strength properties of nickel-based refractory superalloys at normal and elevated temperatures. Int. J. Impact Eng. 2005, 31, 41-54. [CrossRef]

20. Reinhart, W.; Chhabildas, L. Strength properties of coors AD995 alumina in the shocked state. Int. J. Impact Eng. 2003, 29, 601-619. [CrossRef]

21. Whelchel, R.L.; Mehoke, D.S.; Lyer, K.A.; Sanders, T.H., Jr.; Thadhani, N.N. Dynamic yielding and fracture of grade 4 titanium in plate impact experiments. J. Appl. Phys. 2016, 119, 115901. [CrossRef]

22. Kanel, G.I.; Garkushin, G.V.; Savinykh, A.S.; Razorenov, S.V.; Atroshenko, S.A. High-Rate Deformation and Fracture of 15Kh2NMFA Steel under Impact Loading at Normal and Elevated Temperatures. Tech. Phys. 2020, 65, 420-427. [CrossRef]

23. Garkushin, G.V.; Savinykh, A.S.; Razorenov, S.V.; Kanel, G.I. Influence of High-Temperature Annealing on the Resistance to High Strain Rate and Fracture of Tantalum at Temperatures of 20 and $500{ }^{\circ} \mathrm{C}$. Tech. Phys. 2019, 64, 674-679. [CrossRef]

24. Saveleva, N.V.; Bayandin, Y.V.; Savinykh, A.S.; Garkushin, G.V.; Razorenov, S.V.; Naimark, O.B. The Formation of Elastoplastic Fronts and Spall Fracture in AMg6 Alloy under Shock-Wave Loading. Tech. Phys. Lett. 2018, 44, 823-826. [CrossRef]

25. Duffy, T.S.; Ahrens, T.J. Dynamic response of molybdenum shock compressed at $1400^{\circ} \mathrm{C}$. J. Appl. Phys. 1994, 76, 835. [CrossRef]

26. Huang, W.; Zan, X.; Nie, X.; Gong, M.; Wang, Y.; Xia, Y. Experimental study on the dynamic tensile behavior of a poly-crystal pure titanium at elevated temperatures. Mater. Sci. Eng. A 2007, 443, 33-41. [CrossRef]

27. Li, C.; Li, B.; Huang, J.Y.; Ma, H.H.; Zhu, M.H.; Zhu, J.; Luo, S.N. Spall damage of a mild carbon steel: Effects of peak stress, strain rate and pulse duration. Mater. Sci. Eng. A 2016, 660, 139-147. [CrossRef]

28. Kanel, G.I.; Savinykh, A.S.; Garkushin, G.V.; Razorenov, S.V. Effects of temperature and strain on the resistance to high-rate deformation of copper in shock waves. J. Appl. Phys. 2020, 128, 115901. [CrossRef] 